\title{
Workplace Intimacy
}

\section{Andrew Dawson and Simone Dennis}

\begin{abstract}
Aвstract: Amidst massive economic damage tension between the needs to save lives and save jobs has become the basis of a key political fault-line and a matter of daily on-the-ground management during the COVID-19 pandemic. In this article we consider four especially salient changes to work-life wrought by the pandemic: (1) new workplace praxes pertaining to matters of touch; (2) erosion and degrading of the quality of erstwhile intimate relations in certain workplaces; (3) changes to senses of belonging and homeliness in workplaces; (4) and, reflecting on the particular type of work that we do, how the pandemic (and pandemic lockdown especially) is impacting our pedagogical and research practices. Throughout we reveal how the intimacies experienced within workplaces are being transformed - not always eroded or degraded, but also sometimes adapted, sustained in new ways (especially via new communications technologies), and even enhanced.
\end{abstract}

KeYwords: COVID-19, intimacy, pandemic, work, workplace

Less than a year into the COVID-19 pandemic, its economic impacts have already been massive (see Dawson and Dennis 2020a). The world has experienced a stock market crash akin to that in the global financial crisis, the GFC, of 2007-2009; recession; rising unemployment; and a dramatic decline in household economic well-being. And these impacts will intensify and become more widely felt as, facing fiscal crises, states gradually come to withdraw temporary measures designed to ameliorate them. In this context, how to chart a course that balances the saving of lives with the saving of livelihoods has almost certainly become the central dilemma framing the decision-making of nation-states. And this has become, arguably, the central basis of emerging ideological polarities the world over. It is in this context that the final issue of our set of special issues of Anthropology in Action on COVID-19 and the transformation of intimacy tackles the question of workplace intimacy.

The articles in this issue consider the experiences of a range of workplaces and workers: dementia carers; palliative carers; birth doulas; sex workers; traders; domestic workers and professionals who have transformed increasingly into domestic workers because of lockdown; and students, teachers and researchers. Four broad themes emerge within these articles, which frame the structure of the special issue: (1) how the pandemic is engendering new workplace praxes pertaining to matters of touch; (2) how the pandemic is eroding and degrading the quality of erstwhile intimate relations in certain workplaces; (3) how the pandemic is impacting on senses of belonging and homeliness in workplaces; (4) and, finally, reflecting on the particular type of workplace within which most of the contributors labour, how the pandemic (and pandemic lockdown especially) is impacting our pedagogical and research practices. Throughout the issue, the articles reveal how the intimacies we experience within workplaces are being transformed - not always eroded or degraded, but sometimes adapted, sustained in new ways (especially via new communications technologies), and even enhanced.

\section{Touch and No-Touch Intimacy}

Shortly after the beginning of the pandemic, it became clear that specific types of work posed height- 
ened risk. Indoor work, and work in close physical proximity, brought heightened risk of infection. The virus could also hitch itself to precarity, travelling, for example, with workers moving between different jobs in different sites as they cobbled together a living wage: circumstances under which infection control measures could be difficult to secure and control.

While proximity and precarity are significant, employment that entails human touch escalates risk exponentially. This is, of course, cruelly ironic, for human touch is central to care professions and professions that entail the performance of caring (Hochschild 2012). The truth of this is borne out in how care sectors, especially those pertaining to people most vulnerable to succumbing to COVID-19 death, have been disproportionately affected. For example, in Australia 68 per cent of all COVID-19 deaths have occurred in residential aged care settings (Egan 2020). These people are, as Miriam Ticktin (2011) might have put it, 'casualties of care' and thereby one might say 'casualties of intimacy'.

The intimate act of touching, especially in sectors concerned with care and the performance of care, is the focus of this first section of the special issue, which is entitled 'Touch and No-Touch Intimacy.' As a manner of 'incorporating the world, of embodying the actuality (and virtuality) of an other' (Manning 2007: 57), touch is best understood as potentiality, to violence, to intimacy, and, of course, to both at the same time (see Dennis 2016). Reaching out to touch another may be done with caring or harming intention - and even touching with caring intention can cause harm. Being touched involves remaining ever vulnerable to the act's violent potentiality. COVID-19 has made very clear to the authors included in this special issue this vulnerability, how touch has the potential to animate both harm and care, and, equally, how a politics and a now everyday praxis of untouchability makes anew the body politic.

Touch is often indicative of intimate relations between bodies - those we kiss, caress or strike are often entailed in the passions that animate touch and send it outbound to the bodies of our significant others. The intricacies of touches like handshakes indicate a wealth of information about our social relations. And caring touches, such as those made by medical professionals, express a normative vocabulary of the biological body to which we largely agree to conform. But touch is so much more than indicative of close, social and normative hierarchical relations. As Margaret Lyon and Jack Barbalet (1994) argue, touches between parts of bodies create institutions, like the family. Repeated touches make and remake familial relations, and the very deployment of hands that reach out to touch the body parts of others who reach back in return (or perhaps recoil) create that larger social body that we call the family - or at least they do so when familial bodies are collocated. Indeed, as they say, repeated touches between particular body parts might be said to create and define the family. During COVID-19 times, familial bodies were at times required to be together and to sever touching relations with others. A return of one body to the family might put the latter in peril - no bodies could be trusted, and so their touching relations were suspended, controlled, reworked. So too are formalised relations equally built on touch, including the touching relations that pattern contemporary dementia care.

Contemporary dementia care has come to rely increasingly upon a 'relational' approach that promotes carer attentiveness to non-verbal modes of communication and thereby touch (Dawson and Goodwin-Hawkins 2018). The 'therapet' technique, which is the focus of the ethnographic study that informs Cristina Douglas' article on dementia care homes in Scotland, is clearly of this type. Douglas emphasises, through her drawing of the complex categorisation of touch - between task-oriented, professional, caring, and comforting touch, for example - just how crucial touch is in these settings. She argues that the kind of no-touch environment that contagion-control regimes may point us towards is simply not feasible. Indeed, she argues, no-touch may be more lethal than COVID-19 itself (see also Dawson 2020). Douglas, then, calls for a re-imagining of public health measures against the spread of the virus in which touch can be safe (for a description of a practical response to calls of this nature see Streinzer and colleagues in Volume 27, Issue 2).

However, though it must be acknowledged that the requirements of dementia care may be particular, other articles in this section highlight how caring relationships and intimacies are often maintained or built anew in the increasingly no-touch or limitedtouch contexts of the pandemic. Annelieke Dreissen and colleagues explore how the relationships that carers in palliative care settings in England have with their patients, family members and amongst themselves were radically transformed at the height of the pandemic. They describe pressure for a disruption of intimacy, particularly between carers and patients. This was not merely a consequence of the need to refrain increasingly from touch. For example, as the death toll climbed, the carers found themselves as specialists on the matter of dying, switching their 
focus from dealing directly with patients to advising and supporting other colleagues in health care.

Nonetheless, conscious of these pressures, the carers constantly tried to find ways of (re-)establishing intimacy. And in some ways, the peculiarities of the pandemic furnished the grounds for this. Notably, and echoing the findings of clinician-anthropologist Kelly Colas (see Volume 27, Issue 2), Dreissen and colleagues show how, in the milieu of the pandemic, 'classic professional-patient or professional-relative asymmetry was sometimes noticeably dissolved'. In the COVID-19 wards where Colas worked, this was an outcome of the relative absence of knowledge about the disease, while in the palliative care settings researched by Dreissen and colleagues, it was an outcome of a 'collective sense of vulnerability' amongst people who cannot but touch and thereby infect one another potentially.

While the biomedical and more conventional care professionals described by Douglas and Dreissen and colleagues often struggled during the pandemic to maintain intimate relationships with the people they cared for, Angela, N. Castañeda and Julie Johnson Searcy point to one complementary and alternative medicine practice that may have been better placed to transition and maintain intimacies. Their focus is birth doulas in the United States. In essence, doulas are non-medical labour assistants who provide support to birthing women and their partners, communicate the needs of birthing women to medical professionals and, in general, help to create a comfortable and safe birthing environment for birthing women. Through techniques such as 'active listening', ongoing attention to personalising the experience of birthing, and participation in 'multiple embodied practices' with birthing women, doula practice in general lends itself inherently to intimacy. Thus, Castañeda and Searcy found that the levels of intimacy between doulas and their clients survived through disruption wrought during the pandemic. This entailed a complex transference of the intimacies of touch into other sensory modes, a process implied in the addition of 'active' to 'listening' that could not get away with being passive but instead had to be sufficiently present as to be felt as such, as a touch would have been.

The most dramatic instance of pandemic no-touch resulting in an intensification of intimacy comes in Kostia Lennes' study of an escort boy and one of his male clients in Paris. Lennes describes how the payments between the apparent service provider and the apparent customer continued through lockdown and the suspension of physical contact between them.
However, no longer a matter of mere exchange, the payments' meaningfulness was transformed, and other formerly hidden meanings were revealed, for both parties. Payment for one came to be about supporting a lover through tough times and a way of demonstrating affection. And, for the other, its receipt came to be about feeling shame about his requiring a donation. Above all, Lennes' remarkable and, it must be said, remarkably intimate ethnographic study shows how amidst the physical distancing of a no-touch pandemic other forms of intimacy may be made apparent with greater 'intensity'. Furthermore, Lennes goes so far as to suggest that what the pandemic revealed in this case was the existence of an 'authentic intimacy' that presumably may be present but concealed in the normal course of performing sex work.

Each of these cases indicates the importance of examining the sensory modes through which we take intimacy of various kinds to travel. Amongst the many opportunities COVID-19 has presented for analysis comes one in which singular sensory operations are revealed to be unbound from only one kind of operation. Active listening becomes a kind of touch. Touch awaits translation in sex work, revealing simultaneously that which a focus on touch ironically renders invisible: an authentic intimacy.

\section{Eroded and Degraded Intimacies}

In an important article in Volume 27, Issue 2, Carmen McLeod and colleagues remind us of just how important it is to learn to live with rather than against COVID-19. In the same issue, Bryan Lim argues that particular people, including some such as the gay men in his London-based study who have been stigmatised as covidiots because of their infringement of lockdown codes, may play a key role in reminding us 'that there are many ways to live with COVID-19 beyond social distancing'. Lennes' article highlights one such way, and a way that enables not only the continuity, but also the renewal of an intimate way of life. However, the pandemic has contrary impacts and responses too, which this section on 'eroded and degraded intimacies' explores. Two articles, one by Banhishikha Ghosh and one by Ngoc Bich Pham and colleagues, illuminate the erosion of intimate relations in public spheres. And the articles by Pooja Satyogi and Suchismita Chattopadhyay illuminate the degradation - in the sense of them becoming more oppressive - of intimacies that has come about precisely because of their, at least spatial, intensification 
during lockdown (see also McNeilly and colleagues in Volume 27, Issue 2).

Echoing Lennes' findings, Ghosh points out that India's Kotis - men who take on a female gender role in same-sex relationships - who engage in sex work often develop lasting and intimate relationships with their clients. However, in contrast to the Parisian man in Lennes' study, Ghosh observes those intimacies 'withering away because of the pandemic'. This has been, in part, an outcome of clients being confined to their families. However, more significantly, it is an outcome of Kotis' groundless stigmatisation, especially as polluting coronavirus transmitters. Consequently, participation in both sex work and begging were foreclosed. More than a threat to their livelihoods, the situation faced by Kotis during the pandemic represents a threat to their way of life in general, as they are often forced to perform the identities of heterosexual men or women for the purpose of obtaining other forms of employment, and as the 'clandestine cultural families' consisting of their lovers, clients and other Koti community members disappear. Ghosh demonstrates that in the last few decades India has witnessed substantial civil society activism and judicial and legislative development in favour of gender non-conforming communities. However, she points out, 'the pandemic has reversed the process and reinscribed hegemonic normativities surrounding intimacy in ... Indian society by emboldening heteronormative intimate practices at the expense of Koti intimacies'.

Likewise, Pham and colleagues describe how the pandemic is eroding another way of life and its related social intimacies. Their focus is the many women from contexts of poverty who make a living selling breakfasts on the pavements of Ho Chi Minh City in Vietnam. Trade was banned during lockdown, but then allowed to return at its end. However, the authors note, eating behaviours appear to have transformed permanently during lockdown, and consequently, only about 70 per cent of the ladies' trade returned. Nevertheless, many of them adapted, selling online and so on. However, while this may have mitigated economic impacts, the deep interpersonal social networks that the ladies had with customers, shop owners and sister-traders, and which were expressed commonly using kinship terms, have been disrupted for the worse. As the authors put it, 'COVID-19 has disrupted intimate socialities and transformed them into a mediated form that involves digital skills, unfamiliar apps and a new form of social distancing that potentially leaves the ladies selling breakfast on the pavement doing so all alone.'
The highly complementary articles by Satyogi and Chattopadhyay both hinge on the cultural association of lower-caste and pollution in the Indian subcontinent, and how this has been doubled-down upon during the pandemic. As Satyogi puts it (and as Ghosh would surely concur - see above), 'a culturally polluted person [is] rendered even more pestilential because of contagion'. And Satyogi's and Chattopadhyay's shared concern is with how this situation is addressed in high-caste homes, which traditionally have relied upon the domestic assistance of lower-caste women. Satyogi's concern is with the marginalisation and further degradation of such women. It is worth reproducing here one of several examples from her article that is graphically and sickeningly illustrative. She describes: 'In May 2020, Kent, a leading manufacturer of electrical appliances in India, advertised a new product - a flour-kneading and bread-making device. The advertisement asked the potential buyers of the appliance: "Are you allowing your maid to knead atta [flour] dough with her hands? Her hands may be infected. Let automation take care of hygiene this time!"'

In contrast, Chattopadhyay is concerned with the experiences of higher-caste women, especially with the pandemic-induced deficit of domestic help that they face. Previously, domestic help was one of the only feasible ways of enabling them to live up to the cultural expectation of the upper-caste 'superwoman' as Chattopadhyay labels it. This has been developed through successive historical moments and different cultural frameworks. In the Victorian Era, there was an emphasis on the upper-caste woman's expectation of maintaining the nuclear family and managing the household. The late nineteenth century also saw her imagined as an active agent of the nationalist movement from the confines of the home. All the while she was expected to adhere to the upper-caste ideal of being a chaste Hindu daughter/wife/mother. Then, in subsequent generations many upper-caste women were expected to develop professional careers too. Finally, the pandemic itself brought a new layer of expectation. Amidst the loss of domestic labour by which this unreasonable confluence of expectations was sustained, in a clearly andro-centric perception of lockdown entailing an opportunity for self-improvement, she is now also expected to invest time in learning new skills.

\section{Homeliness and Intimacy}

Locked down in the 'pandemic of productivity', as she labels it, Chattopadhyay observes that the 'in- 
timate space of home becomes a site of resentment and frustration for women'. This section explores the intimate environs of homes and how they have been transformed by lockdown and the pandemic generally. We define home not merely as domestic space, but, more broadly and existentially, as being "where one knows oneself best - where "best" means "most", even if not always "happiest"' (Rapport and Dawson 1998: 9). The three articles that the section comprises hint at a perhaps counter-intuitive dialectics of experience between spatial intimacy and growing senses of alienation on the one hand and spatial dislocation and senses of belonging on the other.

Carolina Parreiras' article considers the lockdown experiences of largely single-women heads of household in favelas in Brazil. The situation she describes is of cramped conditions, work overload, increased poverty and increasing food shortage, but also, in the manner described by Nancy Scheper-Hughes (1993) some time ago, a tendency amongst women in such contexts to blame themselves for their negative behaviours towards their children that these conditions provoke. However, what is most striking in Parreiras' article is how the conduct of intimate relations - including between the researcher and research informants - is reconfigured. Writing replaces conversation, as enforced spatial intimacy with some forecloses the possibilities for open communication and engaging in desired intimacies with others. What emerges is that what the pandemic lockdown brings is lost intimacy and a sense of homelessness within homes.

In contrast, in their auto-ethnographic observations of their mediated communications during lockdown, which forced them to be in separate countries, academics Erica Baffelli and Frederik Schröer detect an emerging and peculiar sense of belonging and experience of intimacy. It is, they demonstrate, grounded upon what they describe as the presence of absence. This entails a situation in which spatio-temporal frameworks of interpersonal relations are recoded onto new, virtualised formats, creating, as they put it, 'a kind of a commensurability between the practices of intimacy before the pandemic and those under conditions of absence'. Against a background of dislocation, this works to engender both current intimacies and senses of presence, and senses of the promise of intimacy and presence going into the future.

Last, Brian McGahey's article is a study of an international student dormitory in Copenhagen, Denmark. During lockdown, previously separated spheres of living, work and leisure were brought suddenly together in that one space. Like the multi-tasking women in Hannah McNeilly and Koreen M. Reece's study (see Volume 27, Issue 3), the students worked creatively to resolve the tensions this entailed. For example, they formulated a shared timetable for collective working and socialising. McGahey observed two key outcomes. First, leisure time was marginalised so that, as he says, 'academic demands come out on top and create a sense of constant obligation to work'. These findings echo Chattopadhyay's characterisation of this being a productive pandemic and Rebecca Irons' idea of 'Quarantime', in which lockdown has opened up a 'time prison of temporalities without spaces and ambient intimacies without cessation' (see Volume 27, Issue 3). Second, he observed how the timetable broke down when students synchronised with different international time zones as they kept in regular touch with intimates, family members and friends back home throughout the COVID-19 crisis. In this case, the different dialectics of the pandemic lockdown experience come into tension with one another. As the spatial intimacy of the students appears to lead to growing senses of disjuncture from one another, spatial dislocations from overseas friends and family intensify their intimate relations, and the former seems to occur, in part, precisely because of the latter.

\section{Pedagogical and Research Intimacies}

The final three articles reflect on the particular type of workplace within which most of the contributors labour. Each considers how the pandemic and pandemic lockdown especially is impacting our pedagogical and research practices, and our intimate relations as students, teachers and researchers therein.

The article by Adam Roth and colleagues is a collaborative ethnography by students, tutor and lecturer of their lockdown-enforced Zoom tutorial experiences in the Australian National University's introductory anthropology course. It interrogates a traditional philosophical position which assumes that the bearer of the look is separated from others and from things. The authors find, instead, that Zoom affords an unusual degree of access into one another's intimate lives. And this amounts to much more than seeing into one another's domestic spaces. They observe, rather, that screens are 'vulnerable to our tactile attentions'. For sure, they note that there were moments when they became aware that Zoom teaching was characterised by a sensory paucity. For example, the tutor observes how she 'mourned the loss of the 
nodders', the 'snorters' and 'mmmmmers', those who indicated that they understood what she was saying, or indicated their disagreement with her. However, and in contrast, the Zoom views 'intimated' sensory dimensions of domestic environments and, of course, tastes, as indicated by home décor and the like. Furthermore, the authors observe, Zooming is often experienced as entailing a kind of violent touch. For example, the tutor has the power to 'lower someone's hand' and mute and unmute voices. And, of course, this is a kind of power and capacity not available to her in the classroom.

While Roth and colleagues consider the transformation in lockdown of intimacies within pedagogy, long-time professional collaborators Richard Vokes and Gertrude Atukunda consider transformation of intimacies in relation to the conduct of research, in their case on the matter of infrastructure in Uganda. They highlight a number of dimensions of said transformation. The pandemic, upon which they were no doubt acutely focussed through the media they consumed voraciously in enforced lockdown, wrought a kind of serendipitous transformation of their research focus (Rivoal and Salazar 2013). In particular, they became aware that the most pressing issues of health and well-being raised by the pandemic all stemmed from questions of movement, and so reoriented their own research accordingly. Additionally, the serendipities of lockdown extended also into the area of research design. Responding, we imagine, to health advice during lockdown, both authors took daily walks (see also Skinner in Volume 27, Issue 2). Through these, they became more attentive to issues of movement that, in turn, generated research questions.

However, it is in relation to the social organisation of research that their observations are most revealing. Collaboration took to the medium of Zoom video conferencing, not just between Vokes and Atukunda themselves, but also between a wider network of researchers and informants, whose members were more available than ever because of lockdown. Vokes and Atukunda describe wonderfully the unusually intimate quality of those Zoom-based collaborations. They describe having to communicate from little corners in which they avoid the background noise and interruptions from other members of their households. And, they describe being hunched over laptop screens, leaning into microphones and speakers, and emoting in exaggerated fashions. These experiences produced a 'technique $d u$ corps' of magnified spatial expressions, postures and gestures that 'appeared to intensify the poignancy' and, indeed, the intimacy of the collaborative engagements (see also Simpson in Volume 27, Issue 3). Crucially, Vokes and Atukunda conclude that what took place 'not only conformed to ethnography, but in some ways represented an enhanced version of it, in that it generated evidence about the situation in Uganda that was in certain aspects more detailed than previous methods'.

The concluding article of the special issue, by Genevieve Bell, is, like that by Vokes and Atukunda, one that relies heavily on lockdown-enforced and lockdown-mediated transnational research relationships. Bell begins by observing the highly individuated experiences of COVID-19 faced by research collaborators in and between Australia and the United States. She wonders more generally about how as scholars we can begin to 'talk about life during the pandemic in a way that honours and acknowledges many individual stories, but that also provides us with a broader structure or framework'. For this, she takes inspiration in classical anthropology and, particularly Arnold van Gennep's seminal work on rites of passage (2010 [1960]). This brings us back to the focus of the special issue on 'transformation'. From the chaotic and highly individuated experiential stage of separation from a pre-pandemic world, there emerges, as she describes, a liminal moment in which broad patterns begin to come into play. These concern loosely issues of temporality, intermediation, mobility, relationships, identity and embodiment, which she fleshes out in full in the text. Then, she wonders whether liminality will lead a 'return' to normality or to a world that has been thoroughly transformed, in all manner of ways, including with respect to intimacies.

\section{Conclusion}

The articles in this issue have seized a moment in which sensory engagements with others, and principally touch, have unbound themselves from their habitual modal pathways, in which sites, principally homes, have unbound themselves from habitual securities, and in which activity, principally work, has unbound itself from its usual relations with labouring bodies (see also, Dawson and Dennis 2020b). While the conclusions that authors draw about these unbindings and potentialities are intellectually exciting, the authors share in common a sense that our theorising, our methods and our insights have achieved a kind of fulsomeness and have, as such, delivered to us, as scholars, our own kind of workplace intimacy. COVID-19 has, for many of us, thrown questions 
we already had - about labour, about senses, about time, about societal transformation and more - into a new place, a new time. Attending to these questions, as well as to new ones, has afforded us a kind of scholarly intimacy that, at its very best, will help us to understand the intimate lives of others impacted in their various ways by the pandemic. Indeed, one of the things this triple set of special issues has attempted to do is to turn our intellectual advantage into practical 'anthropology in action'. We hope that the insights of this collection into the intimate worlds of others will be pressed into their service.

Andrew Dawson is Professor and Chair of Anthropology at the University of Melbourne. An ethnographer of human mobilities, he has conducted large-scale research projects in Australia, Bosnia and Herzegovina, England and Ireland.

ORCID: https://orcid.org/0000-0003-3285-3537

Simone Dennis is Head of School, School of Archaeology and Anthropology, at the Australian National University. Her research interests coalesce around phenomenologically informed anthropological theories of embodiment, the senses and power. She has explored these interests in a range of ethnographic contexts, including policing, animal-human interactions in science laboratories, and licit substance use. She is best known for her work on tobacco use and her critical assessments of anthropology's operations in the public arena.

ORCID: https://orcid.org/0000-0002-1071-0095

\section{References}

Dawson, A. (2020), 'Isolation, My Dad, and Me', Pursuit, https://pursuit.unimelb.edu.au/articles/isolation-my-dad-and-me (accessed on 10 August).

Dawson, A., and B. Goodwin-Hawkins (2018), 'Going with the Flow of Dementia: A Reply to Nigel Rapport on the Social Ethics of Care', Australian Journal of Anthropology 29, no. 2: 258-262, doi:10.1111/ taja.12286.
Dawson, A. and Dennis, S. (2020a), 'Microbial Intimacy', Anthropology in Action: Journal for Applied Anthropology in Policy and Practice 27, no. 2: 1-8. doi: 10.3167/aia.2020.270201

Dawson, A. and Dennis, S. (2020b), 'Disaster nativism', Social Anthropology 28, no. 2: 251-253. doi: 10.1111/ 1469-8676.12850

Dennis, S. (2016), 'A Touching Analysis: Of Thirdhand Smoke, Family, Publics, and Touch', Contemporary Drug Problems 43, no. 2: 154-168, doi:10.1177/0091450916645183.

Egan, C. (2020). 'Australia Has One of the World's Highest Rates of COVID Death in Nursing Homes, Royal Commission Hears', HelloCare, 10 August, https://hellocaremail.com.au/australia-one-worldshighest-rates-covid-death-nursing-homes-royalcommission-hears/.

Hochschild, A. R. (2012), The Managed Heart: Commercialization of Human Feeling (Berkeley: University of California Press).

Lyon, M., and Barbalet J. M. (1994), 'Society's Body: Emotion and the "Somatization" of Social Theory', in Embodiment and Experience: The Existential Grounds of Culture and Self, (ed.) T. Csordas (Cambridge: Cambridge University Press), 48-66.

Manning E. (2007), Politics of Touch: Sense, Movement, Sovereignty (Minneapolis: University of Minnesota Press).

Rapport, N. J., and A. Dawson (1998), 'The Topic and the Book', in Migrants of Identity: Perceptions of Home in a World of Movement, (eds) N. J. Rapport and A. Dawson (Oxfor: Berg), 3-16.

Rivoal, I., and N. B. Salazar (2013), 'Contemporary Ethnographic Practice and the Value of Serendipity', Social Anthropology 27, no. 2: 178-185, doi:10.1111/1469-8676.12026.

Scheper-Hughes, N. (1993), Death without Weeping: The Violence of Everyday Life in Brazil (Berkeley: University of California Press).

Ticktin, M. (2011), Casualties of Care: Immigration and the Politics of Humanitarianism in France (Oakland: University of California Press).

Van Gennep, A. (2010 [1960]). Rites of Passage (London: Routledge). 